\title{
De que Modo os Textos Oficiais Prescrevem o Trabalho do Professor? Análise Comparativa de Documentos Brasileiros e Genebrinos
}

(How do Official Texts Prescribe the Teacher's Work? A Comparative

Analysis of the Brazilian and Genebrian Documents)

\author{
Anna Rachel MACHADO \\ (Pontifícia Universidade Católica de São Paulo) \\ Jean-Paul BRONCKART \\ (Universidade de Genebra)
}

\begin{abstract}
In this article we present the results of two documents produced by official agencies that aim at guiding the teachers' work in Brazil and in Switzerland. On the one hand, we focused on detecting the textualization features used to prescribe the teacher's work. Results show that besides the common prescriptive features of the two texts (enunciator's erasure, felicity contract etc), these documents carry a more complex thematic structure, articulating a prescriptive doing, a source-doing and a prescribed-doing. We have also tried to identify the forms of building the object of prescription, which led us to see in both contexts that such object embeds a global pedagogical proposal rather than the actual work of the teachers, the latter not being represented in the texts as actors with a real responsibility in the development of the proposals and, at the same time, presenting the students as inert targets. This work also enabled us to raise some differences in the textualization forms of the prescriptions examined in a way of relating them to the political-economic contexts of the two countries. Eventually, we raise some possibilities about the reasons for the non-consideration of the actual work carried out by teachers in such kind of document.
\end{abstract}

KEY-WORDs: textual analysis; educational work; prescriptive texts; prescriptive doing; prescribed doing.

REsumo: Neste artigo, são apresentados os resultados de análises de dois documentos produzidos por instâncias oficiais para orientar o trabalho dos professores no Brasil e na Suiça. De um lado, buscamos detectar as características da textualização da prescrição

D.E.L.T.A., 21:2, $2005(183-214)$ 
do trabalho do professor. Os resultados mostram que, além das propriedades comuns aos textos prescritivos (apagamento do enunciador, contrato de felicidade etc.), esses documentos se caracterizam por apresentar uma estrutura temática mais complexa, articulando um agir prescritivo, um agir-fonte e um agir - prescrito. Além disso, buscamos identificar as formas de construção do objeto da prescrição, o que permitiu verificar que, nos dois contextos, esse objeto se configura como uma proposta pedagógica global e não como trabalho concreto dos professores, não estando eles representados, nesses textos, como atores que têm uma real responsabilidade no desenvolvimento das propostas e, paralelamente, apresentando-se os alunos como alvos inertes. Esse trabalbo também nos permitiu levantar algumas diferenças das formas de textualização das prescrições examinadas, diferenças essas que relacionamos ao contexto político-econômico dos dois países. Ao final, chegamos a questionamentos referentes às razões da não-consideração do trabalho efetivo dos professores nesse tipo de documento.

PaLAVRAS-CHAVE: análise de texto; trabalho educacional; textos prescritivos; agir prescritivo; agir prescrito.

Esse artigo apresenta uma análise comparativa de partes de dois documentos oficiais que têm por função explícita prescrever o trabalho dos professores: o documento "Parâmetros Curriculares Nacionais para o Ensino Médio (BRASIL/SEF, 1998), editado pelas instâncias governamentais brasileiras da educação e o documento "Les objectifs d'apprentissage de l'école primaire genevoise" (Direction de l'Enseignement Primaire, 2000), editado pelo governo do estado de Genebra (Suíça).

Essa análise inscreve-se no quadro de um projeto de pesquisa mais vasto, desenvolvido colaborativamente pelo grupo de pesquisa ALTER ${ }^{1}$, no Brasil, e o grupo de pesquisa $\mathrm{LAF}^{2}$, em Genebra. Com essa pesquisa,

1 O Grupo ALTER (Análise de linguagem, trabalho educacional e suas relações), que reúne catorze pesquisadores, desenvolve um projeto de pesquisa integrado mais amplo, que já recebeu subsídios do Conselho de Ensino e Pesquisa da PUC/SP e que visa a « desenvolver um aprofundamento teórico-metodológico sobre as relações entre linguagem e trabalho educacional, tomadas no quadro da problemática maior das relações entre discursos, atividades sociais e ações » (Machado 2003:1). Portanto, insere-se na linha de pesquisa em Lingüística Aplicada que vêm investigando as relações entre linguagem e trabalho em geral.

2 O grupo LAF (Langage-Action-Formation) reúne doze pesquisadores da Unidade de Didática das Línguas, da Universidade de Genebra, desenvolve um projeto que visa a analisar como as atividades de trabalho (dentre elas, a do trabalho educacional) é interpretada e construída em diversos textos (orais e escritos) que são produzidos « sobre » essas atividades (cf. Bronckart \& Groupe LAF 2004) 
buscamos, em primeiro lugar, analisar as características da realização efetiva de tarefas de ensino (por meio de gravações áudio-visuais). Em segundo lugar, buscamos analisar as propriedades de textos produzidos "sobre" essas mesmas tarefas, visando, de um lado, identificar de que modo o trabalho se encontra neles representado, reconstruído ou "modelado" e qual é o estatuto atribuído aos actantes que neles se encontram implicados, visando, de um lado, descrever os mecanismos lingüísticos que são mobilizados nesse processo de interpretação linguageira do trabalho. Os textos "sobre" as tarefas do ensino são ou textos produzidos em entrevistas com os professores antes ou depois da realização efetiva de uma tarefa ou documentos produzidos pelas instituições para orientar e prescrever essas tarefas. A análise que apresentamos neste artigo incide apenas sobre documentos institucionais, articulando-se a três objetivos principais. O primeiro é o de identificar a forma como a prescrição do trabalho do professor é textualizado. Os documentos analisados provêm de instâncias que realizam um agir prescritivo $^{3}$ e as questões que colocamos aqui são as seguintes:

- Qual é o gênero de texto que foi adotado para realizar esse agir (sua situação na configuração dos gêneros “de incitação à ação"(Adam 2001))?

- Quais são as características de sua organização geral (planificação, tipos de discurso ${ }^{4}$ mobilizados etc.)?

- De que modo as instâncias enunciativas são apresentadas no texto (ou no paratexto)?

- Por quais procedimentos lingüísticos a prescrição é explicitada, argumentada (explicitação de suas razões e intenções) e organizada?

O segundo objetivo é o de identificar o modo como o objeto da prescrição é construído. Essa prescrição incide sobre o trabalho ou sobre as

\footnotetext{
3 As condições de emprego e o significado dos termos "ato", "atividade", "ação" e "fazer" são, como sabemos, múltiplas e heterogêneas e não temos a pretensão de resolver esse problema neste momento. No quadro deste trabalho, utilizamos o termo "agir" em um sentido genérico e neutro, para designar as intervenções finalizadas de um ser humano no mundo enquanto referentes. Além disso, atribuímos aos termos "atividade" e "ação" um estatuto interpretativo: o primeiro designa uma leitura do agir que implica as dimensões motivacionais e intencionais mobilizadas por um coletivo organizado, enquanto o segundo designa uma leitura do agir que implica as mesmas dimensões, mas quando mobilizadas por uma pessoa particular.

4 Para explicações completas sobre tipos de discurso e sobre as unidades lingüísticas que os caracterizam, consultar, por exemplo, Bronckart (1999) e Machado (1998).
} 
tarefas dos professores, que, desse modo, se constitui como o agir prescrito. Em relação a esse objetivo, colocamos as seguintes questões:

- Quais são os aspectos desse agir prescrito que são tematizados no texto (isto é, em quais aspectos ele se centra: nos determismos externos do contexto do trabalho, ou nos conhecimentos, competências, atitudes dos professores, ou nos alunos enquanto destinatários do agir, ou ainda nas etapas do desenvolvimento concreto do agir)?

- Se o texto se centra no desenvolvimento do agir, qual é o grau de generalidade/especificidade com que são apresentados os acontecimentos ou comportamentos que nele estão implicados?

- Quais são os protagonistas que são postos no/pelo texto como fontes ou actantes do agir prescrito (a instituição, o projeto, a metodologia, os conteúdos, os professores ou os alunos)?

- Em relação a cada um desses protagonistas postos em cena no texto, quais são os que são simplesmente agentivizados, isto é, postos como "agentes” de um processo sobre o qual eles não têm real poder, e quais são aqueles a quem é atribuída uma responsabilidade e que são, portanto, concebidos como "atores" desse processo?

O terceiro objetivo é de ordem comparativa. Como sabemos, os documentos analisados - do Brasil e da Suíça - são produzidos no quadro de projetos de renovação global do ensino, que são bastante similares. Entretanto, os contextos políticos, econômicos e escolares dos dois países são muito diferentes. Em decorrência disso, buscaremos identificar em que medida essas diferenças exercem uma influência sobre a forma como as prescrições são textualizadas (objetivo 1) e sobre a forma como é construído o objeto da prescrição (objetivo 2).

As respostas a essas questões poderão contribuir para a clarificação das concepções sobre o estatuto do trabalho do professor que esses textos veiculam: afinal, qual é o papel atribuído aos professores e quais são os elementos verdadeiramente constitutivos de sua profissão? A nosso ver, " uma concepção ampliada de situação de trabalho » nos leva a considerar que " esta se configura a partir de toda uma rede de discursos proferidos » (Rocha et al. 2002: 79-80), sendo a análise dessa rede o instrumento que nos pode levar a uma compreensão maior das relações linguagem/trabalho. 


\section{As propriedades dos textos prescritivos do trabalho (educacional)}

\subsection{As propriedades do agir prescritivo}

Dentre os conceitos desenvolvidos pelas pesquisas sobre o trabalho, principalmente no campo da ergonomia, já se encontra suficientemente consolidada a distinção entre a dimensão do trabalho prescrito e a do efetivamente realizado. O chamado trabalho prescrito, homogeneizado pela instituição escolar, é freqüentemente delineado nos chamados textos prescritivos, que incidem sobre a organização das classes, a distribuição do tempo disponível, os objetivos do ensino, as rotinas da interação, as ações a serem desenvolvidas etc., enquanto o trabalho realizado varia a cada situação de ensino específica, caracterizando-se por uma transformação permanente das prescrições, que é realizada pelo próprio professor, diante das necessidades específicas com as quais se confronta.

Os textos que apresentam a prescrição de um trabalho, de uma tarefa ou de um ato têm sido, recentemente, objeto de vários trabalhos de análise, que têm apontado a dificuldade de delimitação e de classificação dos gêneros a que eles pertencem. Garcia-Debanc (2001: 67), por exemplo, observa que « os textos que prescrevem ações constituem [...] um conjunto menos homogêneo e menos bem definido que os textos que em geral agrupamos como sendo relatos ». Adam (2001: 11-21), por sua vez, fez uma constatação semelhante e inventariou uma lista desse tipo de textos, que abrange desde enunciados injuntivos a horóscopos, ressaltando a multiplicidade de nomes propostos para designar essa "nebulosa" genérica: textos prescritivos, textos injuntivos, textos procedimentais, textos de incitação à ação etc.

Entretanto, apesar do caráter variável da configuração genérica desses textos, Adam postula que eles apresentam três propriedades enunciativas centrais: são produzidos por especialistas em um dado campo, "cuja presença enunciativa é apagada" (Adam 2001: 21); mencionam um destinatário (ou agente das ações prescritas) com uma forma "aberta [que] pode, assim, ser ocupada por cada leitor-usuário, com a utilização dos pronomes você [vous], nós/a gente [on], seja com um $\varnothing$, seguido de verbo no infinitivo (Adam 2001: 22-23); parecem ser regidos por um "contrato implícito de verdade e de promessa de sucesso [que] garante ao destinatário que, se agir 
conforme todas as recomendações e se respeitar os procedimentos que lhe são indicados, ele atingirá os objetivos visados" (Adam 2001: 22-23). A esse contrato postulado por Adam, denominamos de "contrato de felicidade".

Dadas as características de nosso corpus, interessa-nos aqui lembrar também alguns aspectos da abordagem de Kerbrat-Orecchioni (2001) sobre os atos de linguagem no discurso, embora a autora não trate especificamente de textos prescritivos. Segundo a autora, os textos em geral, do mesmo modo que os enunciados, são globalmente dotados de um valor ilocutório, ou de um macroato, que pode realizar-se direta ou indiretamente, "sob a cobertura" de um outro (Kerbrat-Orecchioni 2001: 35). Examinando vários tipos de macroatos, a autora mostra algumas de suas propriedades, interessando-nos particularmente, devido as características de nosso corpora, sua constatação de que o ato de ordem caracteriza-se por seu caráter autoritário e potencialmente ameaçador das faces dos interlocutores, podendo ele ser "amenizado" por meio de diferentes formulações, como as justificações e as afirmações de desejo do locutor de que a ordem seja cumprida e a constatação de que o ato de doação tem a característica de "propor uma coisa a alguém, colocando-a a sua disposição" (KerbratOrecchioni 2001: 28) e, de forma mais específica, que o ato de "dar um presente" refere-se a uma ação em benefício de um outro, que abre espaço a um agradecimento, desde que esse ato seja percebido como procedente de uma intenção deliberada (cf. Kerbrat-Orecchioni 1992).

Passando para uma revisão dos estudos que se referem especificamente aos textos prescritivos educacionais, verificamos que ainda há muito poucos que tratem dessa questão ${ }^{5}$. A esse respeito, Amigues (2003) observa que essa questão encontra-se geralmente ausente das pesquisas sobre o ensino ou sobre o funcionamento do professor, como se as prescrições não influíssem na ação de ensinar apesar delas determinarem sua realização. Saujat (2002), do mesmo modo, observa a insuficiência desses estudos, considerando ainda que as prescrições são um elemento essencial para a apreensão das propriedades do trabalho educacional.

Embora com uma abordagem da ergonomia da atividade e não de análise de discurso, Amigues (2003) ainda afirma que, ao contrário do que

\footnotetext{
5 Ressalte-se aqui a análisse de Arouca (2003) da Lei de Diretrizes e Bases como documento de prescrição do trabalho educacional.
} 
ocorre em outros domínios de atividade profissional, as prescrições para o trabalho do professor são bastante vagas e imprecisas, o que é também ressaltado por Faïta (2003).

Já com uma abordagem discursiva, Paveau (1999) enumera algumas das características desses textos, das quais destacamos as seguintes:

- Neles, há um autor, ao mesmo tempo institucional e coletivo, cujo estatuto hierárquico é claramente expresso, que institui uma cena com três protagonistas centrais ( $\mathrm{A}$ - o produtor do discurso; $\mathrm{B}-\mathrm{o}$ agente do agir prescrito; $\mathrm{C}-\mathrm{o}$ beneficiário desse agir).

- A seria uma autoridade institucional, cujas marcas enunciativas são apagadas, produzindo-se um efeito de "desencarnação que assegura sua eficácia” (Paveau, 1999: 13); B não é mencionado por marcas de segunda pessoa, mas por um ELE, "o educador", que é determinado por um artigo definido generalizante; e C, o aluno, "representado como sendo o beneficiário da dádiva, $[\ldots .$.$] aparece como o objeto da investigação do locutor, que$ o retrata como um tipo-ideal: o fazer do professor parece realizar este ideal" (Paveau 1999: 19).

- As relações entre esses protagonistas organizam-se em uma estrutura do seguinte tipo: "A diz a B para agir para C".

Dessa forma, a prescrição para o trabalho do professor seria uma prescrição para que ele prescreva o agir de seus alunos.

\subsection{As propriedades do agir prescrito}

Em relação ao agir que o texto prescritivo visa - ou o agir prescrito -, há muito poucos trabalhos que o enfocam. Garcia-Debanc é um dos poucos autores que diz algo respeito, quando discute o problema da produção desses textos quanto ao grau de explicitação dos atos ou dos gestos que devem constituir o agir desejado, pois, segundo a autora, "o redator [parece] posto entre dois princípios contraditórios: de um lado, o problema da completude e da exaustividade e [...], de outro, a necessidade de condensar as informações e de deixar um espaço de inferência para aliviar a carga de trabalho do leitor" (Garcia Debanc 2001: 73). 


\section{Os documentos analisados e seu contexto de produção}

Como sabemos, no Brasil, assim como em toda a América Latina, no decorrer da última década, instaurou-se um importante movimento de reformas dos sistemas educacionais, associado às de outros setores e inspirado na ideologia neoliberal (cf.: Gentili 1998; Meneghel \& Lamar 2002). Central nesse processo foi a produção da reforma da base curricular, iniciada em 1994 pelo Ministério da Educação, a partir de trabalhos de pesquisadores e de especialistas das ciências da educação e de diferentes disciplinas, assim como de diagnósticos e recomendações de instituições internacionais de ajuda ao desenvolvimento. As primeiras versões dos documentos foram difundidas de 1995 a 1997 entre especialistas e responsáveis pelos sistemas de ensino, aos quais foram solicitadas críticas e sugestões. Finalmente, em 1998, foi publicado o conjunto de documentos definitivos, sob o título "Parâmetros Curriculares Nacionais" (PCNs, de agora em diante). A importância que esses documentos passaram a ocupar no contexto educacional brasileiro já se configurava na própria exposição dos níveis de concretização que para eles eram previstos logo no seu lançamento ${ }^{6}$.

Já em Genebra, na mesma década, em 1994, o Departamento da Instrução Pública decidiu também iniciar um processo de renovação, que, em um primeiro momento, envolveu alguns estabelecimentos-pilotos e, em seguida, a partir de 1999-2000, o conjunto das escolas desse cantão suíço. Para isso, diversos documentos foram elaborados, sendo "Les objectifs d'apprentissage de l'école primaire genevoise" (Direction de l'Enseignement Primaire 2000) o mais importante deles, que foi produzido a partir dos trabalhos desenvolvidos em estabelecimentos-pilotos.

A escolha dos segmentos para as análises foi feita depois de exaustiva leitura do conjunto dos documentos, a fim de encontrarmos segmentos que tivessem, do ponto de vista de seu conteúdo explícito, um estatuto equivalente nos dois 'corpora'. Assim, foram selecionadas as páginas de abertura e de fechamento dos dois documentos, as duas "mensagens"

6 Segundo essa exposição, os PCNs deveriam servir de base para programas de formação inicial e contínua de professores, para a avaliação de materiais didáticos e das competências adquiridas pelos alunos, para elaborações curriculares a nível estadual e local, para projetos educativos das escolas e para a planificação dos cursos e da execução dos currículos em sala de aula (cf.: BRASIL/SEF 1998: 51-52). 
oficiais - do Ministro da Educação brasileira e da Presidente do Departamento de Instrução Pública de Genebra (cf. Apêndices 1 e 2, respectivamente) e dois segmentos de textos referentes à concepção de ensino preconizada: do corpus brasileiro, um segmento do documento para a disciplina Ciências Naturais, intitulado "Planificação: unidades e projetos" (cf. Apêndice 3) e, do corpus genebrino, um segmento da Introdução, intitulado "Concepção do ensino: situações de aprendizagem e atividades de estruturação" (cf. Apêndice 4).

\section{Procedimentos de análise dos dados}

Com base no projeto de pesquisa do Grupo LAF (2004) e em pesquisas já desenvolvidas, sobretudo, por Plazaola Giger (2004), foram desenvolvidos vários procedimentos de análise, conforme elencados a seguir.

a) Levantamento do contexto de produção e das características globais dos documentos nos quais se encontram os segmentos analisados, sem análises propriamente lingüísticas, buscando-se identificar a "história" dos documentos, a instituição editorial, os produtores efetivos e os destinatários nomeados.

b) Especificamente em relação aos segmentos selecionados, efetuamos um conjunto de análises para detectar como são textualizados os dois tipos de agir envolvidos nos documentos: o agir prescritivo, que se realiza pelo próprio texto, e o agir prescrito ou a ser realizado. Assim, buscamos:

- identificar o gênero de texto a que pertencem os textos em que se encontram os segmentos;

- identificar o plano global do conteúdo temático desses segmentos;

- identificar o(s) tipo(s) de discurso presentes nos segmentos e os valores das marcas enunciativas, considerando, sobretudo, as formas temporais, as marcas de pessoa e as modalizações;

- identificar as relações predicativas, ou relações predicativas diretas, que se caracterizam pela ausência de modalizador entre o sujeito e o verbo principal, ou as relações indiretas, em que se observa a presença de um modalizador, que pode ter diferentes valores: epistêmico (poder etc.), deôntico (dever, ser preciso etc.), expressivo (pensar, acreditar etc.) ou intencional (querer, tentar, buscar etc.); 
- identificar as unidades centrais que indicam quais são os protagonistas que são colocados em cena no texto ou os "objetos" implicados na prescrição, assim como os papéis sintático-semânticos que lhes são atribuídos. Para isso, identificamos e classificamos os tipos de orações (orações principais e subordinadas, orações com voz ativa (ou neutra) e com voz passiva; orações com verbo conjugado ou com infinitivo) e os sujeitos e os complementos verbais, de acordo com seu papel sintático-semântico, inspirandonos na classificação de Fillmore (1975): Agentivo, o ser animado, responsável por um processo dinâmico; Atributivo (ou Experenciador), o destinatário da atribuição de um processo de estado; Objetivo, o objeto de um processo dinâmico; Beneficiário, o destinatário animado de um processo dinâmico; Instrumental, o ser inanimado que contribui para a realização de um processo dinâmico ou que é sua causa imediata.

Para apreender os diferentes graus de explicitação do agir prescrito, adotamos a seguinte rede de noções (cf. Bronckart \& Machado 2004: 154156):

- Agir prescrito, que constitui o trabalho prescrito para os professores e que pode ser decomposto em tarefas, que podem ser apresentadas sob a forma de uma cadeia de processos, constituída de atos e/ou de gestos.

- No plano motivacional, distinguimos os determinantes externos, de origem coletiva, dos motivos, que são as razões de agir interiorizadas por uma pessoa particular.

- No plano da intencionalidade, distinguimos as finalidades, que são de origem coletiva e socialmente validadas, das intenções, que são as finalidades do agir interiorizadas por uma pessoa particular.

- No plano dos recursos para o agir, distinguimos os instrumentos das capacidades, que são os recursos mentais ou comportamentais atribuídos a uma pessoa particular.

- Em relação aos seres humanos que intervêm no agir, utilizamos o termo actante para qualquer pessoa implicada no agir. No plano interpretativo, utilizamos o termo ator, quando o texto constitui esse actante como sendo fonte de um processo, com capacidades, motivos e intenções, e o termo agente, quando essas mesmas formas não lhe atribuem tais propriedades. 


\section{Resultados das análises}

\subsection{Os elementos das páginas de abertura e de fechamento dos documentos}

Um conjunto de componentes dessas páginas, no documento brasileiro, ressalta seu caráter oficial e nacional: a recorrência do sintagma nominal que constitui o título (Parâmetros Nacionais - cinco vezes), as assinaturas do Presidente da República, do Ministro da Educação, as múltiplas ocorrências de menção ao Ministério da Educação (três vezes), à Secretaria de Educação Fundamental (quatro vezes) e às suas subdivisões e responsáveis. No documento de Genebra, esse caráter oficial aparece menos marcado, encontrando-se a menção ao Departamento de Instrução Pública e à sua Presidente apenas no "copyright" e no interior do Sumário.

Entretanto, nos dois casos, podemos observar uma certa ambigüidade ou dispersão em relação à atribuição da responsabilidade de produção e difusão do documento. No brasileiro, ela é atribuída ao Ministério e à Secretaria, mas a distribuição das ocorrências parece indicar que a responsabilidade maior é da Secretaria, posta sob a autoridade do Ministro, e este, por sua vez, sob a autoridade da Presidência da República. Na situação suíça, a distribuição desse tipo de ocorrências parece indicar uma responsabilidade compartilhada entre o Departamento da Instrução Pública e sua Presidente, de um lado, e a Direção do Ensino Primário de outro.

Quanto à atribuição do estatuto de autor, observamos dois procedimentos diferentes nos dois documentos. No brasileiro, esse estatuto é explicitamente atribuído, na ficha de catálogo bibliográfico, à Secretaria da Educação Fundamental; entretanto, em página de fechamento do volume Introdução, todas as pessoas que contribuíram para a produção dos documentos são citadas, de acordo com o papel que nela desempenharam. Já no documento suíço, esse estatuto é explicitamente atribuído a professores-formadores em geral, mas sem que esses sejam nomeados individualmente.

Em suma, o conjunto dos elementos observados nas páginas de abertura e de fechamento dos dois documentos confirma o caráter institucional e hierarquizado das instâncias das quais provêm, tal como apontado por Paveau (1999). Além disso, mostram o caráter plural dessa instância e, sobretudo, uma certa opacidade em relação à responsabilidade sobre o agir prescritivo e à responsabilidade sobre o conteúdo efetivo da prescri- 
ção, que, diretamente, pode ser atribuída às pesssoas que elaboraram os documentos, mas que, indiretamente, também é das autoridades que os validaram.

\subsection{As «mensagens»}

Como se pode observar nos apêndices 1 e 2 , as duas mensagens apresentam um aspecto visual geral semelhante: são introduzidas por um endereçamento ("Ao professor", "Mesdames, Messieurs", "Chères enseignantes et chers enseignants"), a que se segue o corpo do texto e uma assinatura. A mensagem do Ministro da Educação é constituída por 358 palavras, distribuídas em cinco parágrafos e dez orações, enquanto a mensagem da Presidente do Departamento da Instrução Pública contêm 378 palavras, em sete parágrafos, com 16 frases.

\subsubsection{A organização do conteúdo temático}

\section{Quadro 1 - Plano geral da mensagem brasileira e da suíça}

\begin{tabular}{|l|l|}
\hline Mensagem brasileira & Mensagem suíça \\
\hline $\begin{array}{l}\text { Motivação geral dos documentos: transfor- } \\
\text { mações do mundo moderno e do mundo do } \\
\text { trabalho }\end{array}$ & $\begin{array}{l}\text { Motivação geral do documento: neces- } \\
\text { sidade de referências para a escola pública }\end{array}$ \\
\hline $\begin{array}{l}\text { Ato de entrega dos documentos aos } \\
\text { professores }\end{array}$ & Motivações locais do documento \\
\hline $\begin{array}{l}\text { Finalidades locais dos documentos: a } \\
\text { necessidade de referências comuns para o } \\
\text { ensino nacional }\end{array}$ & Condições de realização do documento \\
\hline Condições de realização dos documentos & Ato de institucionalização do documento \\
\hline $\begin{array}{l}\text { Endereçamento ao professor, com a ex- } \\
\text { pressão de desejo de que os documentos } \\
\text { sirvam para a melhoria do ensino e para seu } \\
\text { desenvolvimento pessoal }\end{array}$ & $\begin{array}{l}\text { Endereçamento aos professores, com a ex- } \\
\text { pressão de estima pelos professores e de } \\
\text { suas capacidades profissionais }\end{array}$ \\
\hline
\end{tabular}

Como mostra o quadro 1, apesar das grandes diferenças entre os contextos de produção, as duas mensagens são muito semelhantes em relação ao conteúdo temático mobilizado e à sua organização. Nessa, há uma estruturação complexa, com menções a um agir-fonte, isto é, o trabalho de produção do documento, a um agir prescritivo central, isto é, o ato que é realizado pelos signatários das mensagens, e a um agir-decorrente (ou 
prescrito), isto é, o agir posterior aos documentos a ser desenvolvido pelos actantes-formadores ou pelos actantes-professores.

Na mensagem brasileira, os três tipos de agir são mencionados sucessivamente, na seguinte ordem:

- o agir prescritivo, com a estrutura: determinantes externos gerais $\longrightarrow>$ ato de entrega $\longrightarrow>$ finalidades desse agir;

- o agir - fonte, com a estrutura: menção aos actantes desse agir $\longrightarrow>$ curso desse agir elencado em atos;

- o agir - decorrente, com menção genérica a diversos atos a serem realizados no quadro do sistema educacional brasileiro.

Já na genebrina, os três tipos de agir são objeto de um encaixamento mais complexo, que se realiza com menções aos diferentes tipos de agir ou a alguns de seus aspectos, na seguinte ordem:

- os determinantes do agir prescritivo (primeiro os gerais, depois os locais), com breve menção genérica ao agir - decorrente esperado;

- o agi $\mathrm{r}-$ fonte, com a estrutura: determinantes externos $\longrightarrow>$ menção aos actantes $\longrightarrow>$ menção aos atos constitutivos desse agir;

- o ato prescritivo, seguido de uma menção ao agir - decorrente, centrada nos atos que os actantes- professores deverão realizar;

- os recursos que esses professores possuem.

Além dessas diferenças de organização, as duas mensagens também se diferenciam pela natureza do ato oficial de prescrição que se realiza: na brasileira, trata-se de suscitar "um debate nacional" e de criar condições para uma melhoria global do sistema educativo; na suíça, trata-se de instaurar um documento de referência compatível com a renovação já em curso.

Entretanto, há semelhanças inequívocas entre as mensagens, em relação às menções ao agir-fonte e ao agir - decorrente, que são as seguintes:

- O agir - fonte é explicitamente apresentado como um "trabalho", qualificado, no caso brasileiro, como "longo" e, no suíço, como "considérable", esses dois adjetivos evidenciando o estatuto argumentativo da men- 
ção ao agir-fonte, pois a seriedade da produção dos documentos apresentase como uma justificativa para o agir prescritivo.

- O agir - decorrente não é qualificado como trabalho. Na brasileira, ele aparece na menção a diversos atos a serem realizados nas escolas (discussão, reflexão, planificação etc.), deixando-se os professores no papel de seus actantes implícitos, e na menção aos efeitos desses atos sobre as capacidades do professor (formação e realização profissional). Já na mensagem suíça, o agir -decorrente aparece na enumeração de diferentes atos de apropriação que os professores poderão-deverão realizar, a que se segue a menção às suas capacidades profissionais, que funciona como argumento de apoio à credibilidade-possibilidade de realização do agir -decorrente.

- O agir prescritivo mostra-se apoiado em três tipos de argumentos. O primeiro é o de que a fonte e os destinatários da prescrição estão ambos submetidos a um conjunto de restrições provenientes de fatos indiscutíveis (as transformações sócio-econômicas, no caso brasileiro; as necessidades da escola genebrina, no outro). O segundo apresenta a seriedade com a qual os documentos foram produzidos, no quadro de um trabalho do qual alguns professores competentes também participaram. Finalmente, com o terceiro, tenta-se levar os destinatários a pensar que, devido à seriedade desse trabalho, o agir -decorrente será indiscutível e necessariamente coroado de sucesso (cf. o "contrato implícito de felicidade" apresentado anteriormente).

\subsubsection{As características textuais globais}

Em relação à questão dos gêneros de texto mobilizados, a mensagem genebrina apresenta-se claramente como uma carta. Já o estatuto genérico da brasileira é menos claro ou de caráter misto: embora apresente algumas características aparentes de carta, como o endereçamento logo no início e o nome do autor abaixo do corpo do texto, a mensagem do Ministro brasileiro não nos parece pertencer inteiramente a esse gênero, pois a generalidade do endereçamento ("Ao professor"), a ausência de data e outros índices menos contextualizadores e/ou interativos parecem indicar que o texto pode pertencer, em parte, ao gênero consigna político-administrativa ou circular político-administrativa e, em parte, ao gênero dedicatória (da doação, feita pelo Ministro, de um «presente » aos professores). 
Como carta, a mensagem suíça instaura uma dupla proximidade: tanto entre a fonte da prescrição e o alvo quanto entre o ato de instauração do documento e de sua aplicação pelos professores. Já a brasileira, enquanto misto de consigna ou circular política e de dedicatória, apresenta um duplo distanciamento: tanto entre a fonte e o alvo do agir prescritivo quanto entre o ato de entrega dos documentos e o agir-decorrente.

Talvez possamos interpretar essa diferença na mobilização de gêneros diferentes pelas duas mensagens levando em conta as diferenças dos contextos de produção dos documentos: à considerável diferença de amplitude dos sistemas educacionais envolvidos e, conseqüentemente, ao caráter fortemente centralizador da instituição educacional brasileira, que contrasta com o aspecto quase familiar e a "preocupação democrática" (real ou simbólica) das instituições genebrinas.

Quanto aos tipos de discurso mobilizados, as semelhanças são mais evidentes. Nos dois casos, os segmentos referentes ao agir prescritivo e ao agir-fonte apresentam-se em uma fusão do tipo de discurso interativo e do teórico, característica de muitas produções verbais das esferas políticas, científicas e/ou educacionais (cf. Bronckart 1997: 194-196), enquanto os segmentos referentes ao agir - decorrente são construídos em relato interativo. Correspondentemente, a distribuição dos tempos verbais é globalmente equivalente: os tempos de base, nas duas mensagens, são os presentes e os infinitivos, acompanhados de formas do passado e do futuro. Observese ainda que as formas do presente apresentam, ora um valor genérico, ora de simultaneidade, conforme ocorram nos segmentos com dominância de discurso teórico ou de discurso interativo, respectivamente. Já as formas do passado, como previsível, aparecem exclusivamente nos segmentos sobre o agir-fonte e as formas do futuro, quase que exclusivamente nos segmentos sobre o agir - decorrente. Observe-se também a quantidade relativamente grande das formas passivas (com oito e seis ocorrências, na mensagem brasileira e na suíça, respectivamente), características do discurso teórico.

\subsubsection{A textualização do agir prescritivo}

Nas duas mensagens, as fontes do agir prescritivo são apresentadas como sendo os próprios autores, que, entretanto, são pouco marcadas por meio de unidades dêiticas. Assim, na brasileira, além dos elementos pa- 
ratextuais, há apenas três formas verbais na primeira pessoa do plural, ora com valor genérico, envolvendo o destinatário ("vivemos"), ora de forma particular, designando o actante responsável pelo processo do ato de entrega (entregamos) e o actante do processo de desejo relacionado ao agir decorrente ("esperamos"). Além dessas formas verbais, ocorrem ainda dois determinantes possessivos de primeira pessoa do plural, mas com valor genérico e argumentativo ("nosso país", "nossos jovens"). Já na genebrina, além das indicações paratextuais, a fonte da prescrição é explicitada por dois pronomes da primeira pessoa do plural ("me" e "nous"), que se encontram no endereçamento final aos professores, designando o actante do processo de estima a esses mesmos professores.

Quanto ao alvo do agir prescritivo, os dois textos se diferenciam claramente. Na mensagem brasileira, embora seja feito um endereçamento explícito ao professor, o alvo real parece ser o conjunto do sistema educacional do país, sendo poucas as marcas de referência direta aos destinatários, com apenas três ocorrências de possessivos referentes à segunda pessoa do singular ("sua", "suas"), justamente no parágrafo referente ao agir-decorrente, em uma clara busca de envolver o destinatário na efetivação dos efeitos desejados pela fonte prescritora. Já na genebrina, o alvo parece ser exclusivamente os professores, indicados explicitamente como destinatários pela fórmula nominal inicial em função de vocativo ("Cher-e-s enseignant-e-s") e por onze ocorrências do pronome "vous" e seis ocorrências de determinantes possessivos ("votre", "vos"), que assinalam o caráter interativo requerido pelo gênero carta.

A explicitação do agir prescritivo também é feita de forma diferente: na brasileira, ele é representado como uma simples «entrega» («entregamos aos professores»), com o autor/actante manifestando explicitamente seus sentimentos e suas intenções («com imensa satisfação», "com a intenção de», «esperamos») e, portanto, sua subjetividade e seu estatuto de ator. Já na mensagem suíça, o ato de instauração do documento é formulado em frase impessoal («Il s'agit d'un document officiel qui devient désormais la référence...»), não se fazendo nenhuma menção a sentimentos ou intenções do autor-actante.

\subsubsection{A construção dos "objetos" das prescrições}

As análises desenvolvidas permitiram-nos detectar quatro protagonistas centrais implicados e/ou visados pelo agir prescritivo: na brasileira, a 
demanda social, os documentos, os professores e os jovens; na genebrina, a escola, o documento, os professores e os alunos. Além disso, permitiramnos identificar o estatuto semântico-sintático de cada um desses protagonistas, como mostrado no quadro 3 .

\section{Quadro 3 - Estatuto sintático-semântico dos protagonistas centrais das mensagens ${ }^{7}$}

\begin{tabular}{|c|c|}
\hline $\begin{array}{l}\text { Protagonistas centrais } \\
\text { na mensagem brasileira }\end{array}$ & $\begin{array}{l}\text { Protagonistas centrais } \\
\text { Na mensagem genebrina }\end{array}$ \\
\hline $\begin{array}{l}\text { Demanda social } \\
1 \text { agentivo em principal ativa (impõe) }\end{array}$ & $\begin{array}{l}\text { École } \\
2 \text { atributivos em principal ativa (a besoin, est en } \\
\text { rénovation) }\end{array}$ \\
\hline $\begin{array}{l}\text { Documentos } \\
2 \text { atributivos em principal ativa (são o } \\
\text { resultado, trazem a marca) } \\
2 \text { objetivos em subordinada passiva (foram } \\
\text { elaborados, deverá ser revista) } \\
2 \text { objetivos em subordinada infinitiva passiva } \\
\text { (serem analisados, serem debatidos) } \\
1 \text { objetivo em principal ativa (entre- } \\
\text { gamos) } \\
2 \text { objetivos em principal passiva (foram } \\
\text { elaborados, foram elaborados) } \\
2 \text { instrumentais em subordinada ativa } \\
\text { (sirvam de apoio, possam contribuir) }\end{array}$ & $\begin{array}{l}\text { Document } \\
2 \text { atributivos em principal ativa (constituent, } \\
\text { devra être applicable) } \\
1 \text { objetivo em subordinada passiva (est remis) } \\
4 \text { objetivos em subordinada infinitiva (élaborer, } \\
\text { examiner, améliorer, approprier) } \\
5 \text { agentivos em principal ativa (répondent, } \\
\text { s'intègre, devient, sera appelé à évoluer, offre) }\end{array}$ \\
\hline $\begin{array}{l}\text { Professores } \\
1 \text { agentivo em subordinada passiva (rea- } \\
\text { lizado por) } \\
1 \text { agentivo em subordinada ativa (atuam) } \\
2 \text { agentivos em subordinada infinitiva } \\
\text { passiva (serem analisados e debatidos) } \\
1 \text { beneficiário em principal ativa (entre- } \\
\text { gamos) } \\
1 \text { instrumental em subordinada ativa (contou } \\
\text { com a participação de) }\end{array}$ & $\begin{array}{l}\text { Enseignant-e-s } \\
1 \text { agentivo em principal ativa (pourrez faire } \\
\text { appel) } \\
3 \text { agentivos em subordinada ativa (devez pouvoir } \\
\text { vous appuyer, souhaitez, estimerez) } \\
2 \text { agentivos em subordinada infinitiva ativa } \\
\text { (approprier, examiner) } \\
1 \text { beneficiário em principal ativa (permettre) } \\
1 \text { beneficiário em subordinada passiva (est remis) } \\
2 \text { atributivos em principal ativa (êtes, assurez la } \\
\text { qualité) } \\
1 \text { objetivo em subordinada passiva (ont été } \\
\text { appelé) }\end{array}$ \\
\hline $\begin{array}{l}\text { Jovens } \\
2 \text { beneficiários em subordinada ativa } \\
\text { (permitam, permitam), }\end{array}$ & $\begin{array}{l}\text { Elèves } \\
1 \text { beneficiário em subordinada infinitiva (donner } \\
\text { la possibilité), que funciona, ao mesmo tempo, } \\
\text { como agentivo em subordinada infinitiva } \\
\text { (acquérir). }\end{array}$ \\
\hline
\end{tabular}

\footnotetext{
No quadro, indicamos o papel sintático-semântico dos protagonistas, seguido do tipo de frase em que se encontram e, entre parênteses, em itálico, os verbos correspondentes e, em itálico + negrito, os modalizadores.
} 
Na mensagem brasileira, observamos que é "a demanda social" que é colocada como indiscutível e como ator central do processo de prescrição (é ela que «impõe»), enquanto na genebrina, são "as necessidades da escola" (e da renovação) que são colocadas como estados evidentes. Em relação aos documentos, nas duas mensagens, eles são apresentados como o produto de um agir-fonte e como o objeto do ato de entrega, mas de forma um pouco diferente em cada uma. Na brasileira, atribui-se a eles o estatuto de instrumento desencadeador do processo de debate desejado pela fonte prescritora, esperando-se que ele sirva de instrumento para o desenvolvimento do agir - decorrente; enquanto na genebrina, o documento é elevado à condição de verdadeiro ator do processo de renovação (cf. os agentivos em principal ativa), mas atribuindo-se aos professores recursos pessoais que lhes permitirão a apropriação dos conteúdos veiculados.

Quanto aos professores, nas duas mensagens, só uma parte deles, os que participaram da produção, da prescrição são tratados como reais atores do processo do agir-fonte, em uma estratégia claramente argumentativa. Entretanto, na brasileira, fora esses professores - prescritores, os demais são colocados apenas no papel de beneficiários - ou de destinatários primeiros - do ato de entrega e dos efeitos dos documentos. Já na genebrina, embora esse papel também seja atribuído aos professores, estes ainda aparecem como atores dos processos de apropriação e de formação ("l'année scolaire devrait vous permettre de vous l'approprier"), com motivações ("si vous le souhaitez; vous estimerez") e também como actantes dotados de recursos pessoais propícios ao desenvolvimento do agir prescrito ("Vous êtes sur le terrain quotidien de l'école. Vous assurez, avec vos compétences professionnelles et votre engagement, la qualité de l'école primaire genevoise.»).

Finalmente, ainda nas duas mensagens, os “jovens" e os "élèves” apresentam-se no papel de destinatários últimos dos processos de renovacão prescritos, que, automatica ou necessariamente, deles se beneficiarão.

Observe-se ainda que, na mensagem brasileira, ao contrário do que se poderia esperar de um texto prescritivo, não há modalizações deônticas em referência direta ao trabalho do professor. As modalizações que aparecem referem-se ao posicionamento da(s) autoridade(s) prescritora(s) diante dos documentos: a suas finalidades ("pretende-se criar"), à necessidade de revisão futura dos documentos ("deverá ser revista") e ao desejo de que sejam 
eficazes ("esperamos que possa contribuir"). Já na mensagem suíça, há modalizações deônticas que se referem diretamente ao trabalho do professor: ou indicando a obrigatoriedade de aplicação do documento ("devra être applicable par tous"), ou a de que os professores nele se apóiem ("devrez pouvoir vous appuyer").

\subsection{Os segmentos referentes à concepção de ensino}

\subsubsection{Características textuais globais}

O segmento referente à concepção de ensino do documento brasileiro é constituído por 327 palavras, em sete parágrafos, com treze orações. O segmento do documento genebrino correspondente apresenta 295 palavras, distribuídas em quatro parágrafos. Os dois segmentos são bastante semelhantes quanto a suas características genéricas e discursivas. Em relação ao gênero, as duas partes dos documentos das quais os segmentos foram extraídos mobilizam claramente o gênero manual. Em relação aos tipos de discurso, os dois segmentos apresentam todas as características do tipo de discurso teórico. Dentre elas, a distribuição das formas verbais, que é equivalente nos segmentos: os tempos de base são o presente, com valor genérico (com 18 ocorrências, no brasileiro, e 17, no suíço) e o infinitivo (com cinco e nove ocorrências, respectivamente), acompanhados de uma forma do futuro.

De forma semelhante também, nos dois segmentos, a fonte da prescrição não é mencionada explicitamente. $\mathrm{O}$ alvo da prescrição é, em princípio, o conjunto dos professores, que não são referidos por unidades dêiticas, mas tratados em terceira pessoa (por três ocorrências de "o professor" e três de "l'enseignant-e"). As referências aos alunos são mais numerosas do que as referências ao professor (por sete substantivos, na brasileira; e por seis substantivos e dois pronomes, na genebrina).

\subsubsection{As relacões de agentividade nos "objetos" da prescrição}

Em relação ao tratamento que é dado aos "objetos" da prescrição, as semelhanças entre os segmentos são evidentes. Os protagonistas centrais colocados em cena são os actantes "metodologia", "professores" e "alunos". 
As ocorrências das frases sem sujeito gramatical e das frases que colocam a metodologia de ensino prescrita como actante são mais numerosas do que as que colocam o professor ou o aluno, conforme podemos verificar no quadro 5 , que mostra o levantamento das ocorrências das frases sem sujeito ou com sujeito indeterminado, e no quadro 6, que apresenta as diferentes ocorrências dos sintagmas que remetem aos protagonistas e o papel sintático-semântico desses sintagmas.

\section{Quadro 5 - Levantamento das ocorrências das frases de caráter impessoal}

Segmento brasileiro

6 frases nominalizadas (delimitação, solicitação, investigação, utilização, sistematização, apresentação).

1 frase impessoal com nominalização (há confrontação).

Segmento suiço

4 frases impessoais (il s'agit d'exercer, il convient d'identifier, il suffira, il ne faut pas confondre).

1 frase ativa com pronome indeterminado (si on veut assurer).

4 subtítulos sob forma de infinitivas (proposer, articuler, reconnaître, différencier).

3 frases subordinadas infinitivas (leur permettre de donner, faciliter, intervenir).

Em relação às frases sem sujeito gramatical e as que mobilizam a metodologia como actante, os dois segmentos apresentam diferenças claras em relação à sua estrutura e a seus referentes: no brasileiro, as frases sem sujeito são constituídas por nominalizações e referem-se a processos que são da responsabilidade do professor, ou do aluno ou indeterminada; enquanto, no suíço, as frases sem sujeito gramatical são constituídas por fórmulas de impessoalização ou por infinitivos, referindo-se a processos que são da responsabilidade exclusiva do professor.

Outra diferença aparece em relação aos papéis sintático-semânticos atribuídos aos protagonistas, especificamente em relação aos elementos da metodologia: no segmento brasileiro, encontram-se, na sua maioria, como atributivos; enquanto, no suíço, distribuem-se entre o atributivo e o agentivo, com modalizações deônticas associadas a este último papel.

Entretanto, as semelhanças são evidentes em relação às ocorrências das modalizações e aos papéis atribuídos aos professores e aos alunos: as 
Machado \& Bronckart: De que Modo os Textos Oficiais Prescrevem... 203

\section{Quadro 6-Ocorrências dos sintagmas que se referem aos protagonistas centrais e seu papel sintático-semântico nos segmentos referentes à concepção de ensino}

\begin{tabular}{|c|c|}
\hline Segmento brasileiro & Segmento suíço \\
\hline $\begin{array}{l}\text { Metodologia } \\
5 \text { atributivos em principal ativa (são, é, } \\
\text { comporta, são, podem constituir) } \\
1 \text { atributivo em principal passiva (é composta) } \\
1 \text { atributivo em subordinada ativa (podem } \\
\text { consistir) } \\
1 \text { instrumental em subordinada ativa (se abre) } \\
1 \text { objetivo em principal passiva (devem ser } \\
\text { registrados) }\end{array}$ & $\begin{array}{l}\text { Methodologie } \\
2 \text { atributivos em principal ativa (ne peut se } \\
\text { concevoir, peut se concrétiser) } \\
1 \text { agentivo em principal ativa (doit permettre) } \\
1 \text { agentivo em subordinada ativa (obligent à } \\
\text { mettre) }\end{array}$ \\
\hline $\begin{array}{l}\text { Professor } \\
1 \text { agentivo em principal ativa (propõe) } \\
2 \text { agentivos em subordinada ativa (organiza, } \\
\text { explica) } \\
1 \text { agentivo em frase nominalizada (apre- } \\
\text { sentação por) }\end{array}$ & $\begin{array}{l}\text { Enseignant-e } \\
1 \text { agentivo em principal ativa (pourrez faire } \\
\text { appel) } \\
3 \text { agentivos em subordinada ativa (devez pouvoir } \\
\text { vous appuyer, souhaitez, estimerez) } \\
1 \text { agentivo em subordinada infinitiva } \\
\text { (approprier) } \\
2 \text { atributivos em principal ativa (êtes, assurez } \\
\text { la qualité) } \\
1 \text { beneficiário em principal ativa (permettre) }\end{array}$ \\
\hline $\begin{array}{l}\text { Alunos } \\
2 \text { agentivos em principal ativa (se manifestam, } \\
\text { reestruturam) } \\
1 \text { beneficiário em subordinada ativa (se abre } \\
\text { para) } \\
1 \text { agentivo em frase nominalizada (auto- } \\
\text { avaliação dos) } \\
1 \text { instrumental em principal ativa (pro- } \\
\text { põe com) } \\
1 \text { objetivo em principal ativa (interessa) }\end{array}$ & $\begin{array}{l}\text { Elèves } \\
3 \text { agentivos em principal ativa (expriment, } \\
\text { proposent, font) } \\
4 \text { beneficiários em principal ativa (propose, } \\
\text { s'agit d'exercer, permettre de donner, } \\
\text { permettre) }\end{array}$ \\
\hline
\end{tabular}

modalizações ocorrem exclusivamente nas frases sem sujeito gramatical e nas que mobilizam a metodologia como actante, enquanto que, nas frases em que o professor ou o aluno são mobilizados como actantes, não há nenhuma modalização, tendo elas, portanto, um valor assertivo; o papel sintático-semântico dos sintagmas referentes aos professores é exclusivamente o Agentivo, havendo uma só ocorrência de Beneficiário no segmento suíço, mas ocorrência essa que é combinada a uma relação agentiva indireta (cf. "permettre aux enseignants l'intervention"); a metade dos papéis sintático-semânticos dos sintagmas referentes aos alunos é da ordem do Agentivo, com a outra metade sendo distribuída em papéis de outra ordem, como Beneficiário, Instrumental e Atributivo. 


\subsubsection{Os processos constitutivos do agir prescrito}

Como fica evidente, nos dois segmentos, o agir prescrito e a agentividade dos professores mostra-se mais acentuada do que nas mensagens introdutórias aos documentos. Verificada essa característica, buscamos identificar como se distribuem os processos constitutivos do agir prescrito que são mencionados, em função dos actantes que são postos como responsáveis por eles, o que apresentamos no quadro 7.

Quadro 7 - Distribuição dos lexemas que denotam processos do agir prescrito em função dos actantes postos como responsáveis por eles ${ }^{8}$

\begin{tabular}{|l|l|l|}
\hline Responsável & Segmento brasileiro & Segmento suíço \\
\hline Professor/Enseignant(e) & Propor (1) & Proposer (2) \\
& Apresent-ar-ação (3) & Différenti-er -ation (3) \\
& Passar (1) & Articuler (1) \\
& Delimitar (1) & Faire un choix (1) \\
& Organizar (1) & Intervenir (1) \\
& Iniciar (1) & Exercer (1) \\
& Solicitar (2) & Identifier (1) \\
& Explicar (1) & Reconnaître (2) \\
& Registrar (2) & \\
\hline Alunos/Elèves & Realização (1) & Mise en œuvre (1) \\
& Participação (1) & Donner sens (1) \\
& Auto-avaliação (1) & Faire (1) \\
& Manifestar erros (1) & Exprimer (1) \\
& Reestruturar (1) & Proposer (1) \\
\hline Indeterminado & Investigação (1) & Surmonter (1) \\
& Utilização (1) & Résoudre (1) \\
& Confrontação (1) & Faciliter (1) \\
& Sistematização (1) & \\
& Apresentação (1) & \\
\hline
\end{tabular}

Mais uma vez, as semelhanças são evidentes. Nos dois segmentos, a maioria dos processos sob responsabilidade do professor refere-se à aplicação dos princípios metodológicos gerais e à organização das tarefas (oito processos em cada segmento). Em relação aos processos citados acima, são menos numerosas as ocorrências de processos que envolvem um agir concreto do professor relacionado ao aluno, como solicitar, explicar, exercer (três, no caso brasileiro e um no suíço). Do mesmo modo, são menos nu-

8 Foram considerados aqui os actantes mencionados explicita ou implicitamente. 
merosas as ocorrências de processos que implicam recepção do agir do professor pelos alunos, como "registrar", "identificar", "reconhecer", com duas ocorrências em cada segmento. Já os processos sob responsabilidade dos alunos distribuem-se eqüitativamente, nos dois segmentos, entre processos decorrentes da metodologia (três ocorrências nos dois casos) e processos referentes a sua iniciativa pessoal (duas ocorrências nos dois casos).

Esses resultados das análises confirmam o estatuto motor que é dado aos princípios metodológicos e a pouca tematização das interações que podem se desenvolver entre os professores e os alunos: mesmo que, algumas vezes, o professor seja posto na realização de atos de solicitação e de recepção e o aluno posto como realizando um agir próprio, os dois são colocados em relação direta, a não ser em duas orações do segmento genebrino.

\subsubsection{Comentários sobre os segmentos referentes à concep̧ão de ensino}

Em sua organização discursiva, esses dois segmentos do gênero manual apresentam, ao contrário das mensagens anteriormente analisadas, as características essenciais apontadas por Adam (2001) e Paveau (1999) para esse tipo de texto: completo apagamento da fonte da prescrição; menção do alvo sob uma forma nominal generalizadora; contrato implícito de felicidade; apresentação do aluno como um tipo-ideal e como alvo maior, beneficiário último do processo a ser desenvolvido.

Em relação aos "objetos" da prescrição, são os princípios gerais e as metodologias que são erigidos em atores ou motores do agir-decorrente, pois são eles os únicos protagonistas aos quais são atribuídas dimensões de uma semântica da atividade (determinações, intenções, poder-fazer).

Quanto aos professores, eles são postos como adjuvantes ou como instrumentos de um processo que se apresenta com um caráter inelutável ou quase mecânico, sendo seu trabalho maior posto como sendo o trabalho de aplicar os princípios propostos. Mesmo quando é evocado o seu agir concreto (ativo ou receptivo) em relação aos alunos, eles não são nunca postos como sendo dotados das dimensões de uma semântica da ação. Enfim, os alunos, ao mesmo tempo em que são postos como beneficiários do agir do professor e como tendo um espaço de agir próprio, também não são postos 
como detentores das dimensões de uma semântica da ação. Como observamos em nosso comentário interpretativo sobre as duas mensagens analisadas, esses dois aspectos nos parecem intimamente ligados: o professor só poderia ser colocado como ator na medida em que se tematizassem as possíveis reações dos alunos a suas intervenções, porque o trabalho próprio do professor consiste exatamente em uma estabelecer uma negociação permanente entre as injunções provenientes dos princípios metodológicos e as reações concretas provenientes da classe ou dos alunos.

\section{Conclusões: o professor e seu trabalho nos textos de prescrição}

Os resultados de nossas análises permitem-nos afirmar que os documentos de nosso corpus, apesar de não apresentarem uma estrutura prescritiva canônica, funcionam nitidamente como textos prescritivos do trabalho do professor. A análise das mensagens, reformulada em termos de macroatos de linguagem, permite-nos distinguir dois procedimentos diferentes levados a cabo: no caso brasileiro, o ato explícito apresenta-se, literalmente, como sendo o da "doação de um presente" aos professores, que acabam, desse modo, sendo colocados no papel de devedores, com a obrigação de dar uma resposta positiva ao ato efetivado pelo doador, resposta essa que deve vir ao encontro das expectativas expressas. Entretanto, a própria insistência sobre o estatuto oficial e hierárquico da fonte da prescrição, que detectamos, mostra-nos que, de fato, esse ato explícito funciona como amenizador do ato derivado, efetivo, que é claramente o de ordem ou de prescrição semi-jurídica. Já no caso suíço, esse caráter jurídico é menos marcado; mas, em contrapartida, o macroato é mais explicitamente de ordem, não sendo amenizado por outro tipo de ato.

Entretanto, paradoxalmente, nas duas mensagens, observamos que o agir prescrito é tratado apenas em suas dimensões periféricas. Ora, se admitimos que esse agir prescrito é o "objeto" real a que visa o agir prescritivo e se observamos que ele só é mencionado em relação aos efeitos gerais que podem ser produzidos a partir da prescrição, podemos afirmar que ele, de fato, não é representado como um trabalho a ser desenvolvido em atos. Conseqüentemente, consideramos que os professores não são representados como atores reais, com motivos e intenções próprias, a não ser na mensagem suíça, mas, ainda aí, como atores apenas do processo de apropriação 
do documento. Quanto aos alunos, apesar da ênfase ideológica, presente nos dois documentos, sobre a necessidade de que sejam consideradas suas características cognitivas, ativas etc., de acordo com a fórmula-padrão «o aluno no centro do dispositivo", eles aparecem, de fato, como objetos inertes, totalmente submetidos ao processo a ser desenvolvido.

Do mesmo modo, as análises dos segmentos sobre a concepção de ensino confirmam o que acabamos de afirmar. Neles, os princípios gerais e a metodologia é que se encontram elevados à condição de atores ou de motores do agir prescrito, pois só a eles são atribuídas as dimensões de uma semântica da ação (como determinações, intenções, recursos). Os professores, por sua vez, são postos no papel de adjuvantes ou de instrumentos de um processo de caráter inexorável ou quase mecânico, considerando-se ser seu trabalho primordial a simples aplicação dos princípios propostos. Mesmo quando seu agir concreto (ativo ou receptivo) em relação aos alunos é considerado, não lhes é atribuído o papel de actantes dotados das dimensões de uma semântica da ação. Enfim, os alunos são apresentados como beneficiários do agir do professor, sendo-lhes assegurado um espaço próprio para seu agir, mas também não sendo tomados como portadores dessas dimensões.

De fato, parece-nos que os papéis atribuídos aos professores e aos alunos, nos dois segmentos, encontram-se em uma relação direta, já que só poderia apresentar o professor na condição de ator, se as possíveis reações dos alunos a suas intervenções fossem tematizadas, já que seu trabalho consiste, fundamentalmente, em estabelecer uma negociação permanente entre as injunções provenientes dos princípios metodológicos prescritos e as reações concretas de seus alunos.

A partir dos resultados apresentados neste artigo, podemos levantar algumas questões intrigantes para o estudo das relações entre linguagem e trabalho educacional: Por que o trabalho efetivo dos professores aparece constantemente oculto e, conforme indicam diferentes pesquisas, até mesmo em seu próprio discurso)? Se admitimos, ao lado de outros autores, que as prescrições são necessárias para orientar qualquer trabalhador em sua atividade profissional, em que medida e de que forma o professor consegue atuar com prescrições que, na verdade, não se referem a seu agir concreto? Em que recursos se apóia para suprir essa falta? Enfim, e in cauda venenum, em que medida, ao negarem o estatuto de ator ao professor nos textos 
prescritivos de seu trabalho, as próprias instituições educacionais prescritoras não estariam sustentando uma "imagem negativa" e uma "crise de identidade profissional" do professor, tão apontadas por pesquisadores dos problemas educacionais contemporâneos?

E-mail: arachelmachado@uol.com.br

Recebido em dezembro de 2003

Aprovado em maio de 2005

\section{REFERÊNCIAS BiBLIOGRÁFICAS}

AdAm, Jean-Michel. 2001. Entre conseil et consigne: les genres de l'incitation à l'action, Pratiques, 111/112: 7-38.

Amigues, René. 2003. Pour un approche ergonomique de l'activité enseignante. Documento de trabalho. s/p.

Arouca, Márcia. 2003. Do discurso à educação no Brasil: uma interlocução com a Lei de Diretrizes e bases 9.394/96. (Tese de doutorado em Linguística Aplicada e Estudos da Linguagem). São Paulo: Pontifícia Universidade Católica de São Paulo.

Brasil/SEF. 1998a. Parâmetros Curriculares Nacionais: terceiro e quarto ciclos do ensino fundamental: introdução aos parâmetros curriculares nacionais. Brasília: MEC/SEF. Version PDF, no site www.mec.gov.br, consultado entre 01/ 04/2003 a 01/07/2003.

Brasil/SEF. 1998b. Parâmetros Curriculares Nacionais: terceiro e quarto ciclos do ensino fundamental: ciências naturais.

Bronckart, Jean-Paul. 1999. Atividades de linguagem, textos e discursos. Tradução de Anna Rachel Machado e Péricles Cunha. São Paulo: Educ.

. 1997. Activité langagière, textes et discours - pour un interactionisme socio-discursif. Lausanne: Delachaux et Niestlé.

\& Machado, Anna Rachel. 2004. Procedimentos de análise de textos sobre a trabalho educational. In: Anna Rachel Machado (Org.) O ensino como trabalho. Londrina: Eduel: 131-166.

\& Groupe LAF. 2004. Agir et discours en situation de travail. Cahiers de la section des sciences de l'éducation (Genève), 103.

Direction de l'Enseignement Primaire. 2000. Les objectifs d'apprentissage de l'école primaire genevoise. Genève, Département de l'Instruction Publique. 
FAïTA, Daniel. 2003. Apport des sciences du travail à l'analyse des activités enseignantes. Documento de trabalho.

Fillmore, Charles John. 1975. Quelques problèmes posés à la grammaire casuelle. Langages, 38: 65-80.

Garcia-Debanc, Claudine. 2001. Les genres du discours procédural: invariants et variations. Pratiques, 111/112: 65-76.

GeNTILI, Pablo. 1998. A falsificação do consenso: simulacro e imposição na reforma do neoliberalismo. Petrópolis: Vozes.

Kerbrat-Orecchioni, Cathérine. 1992. Les interactions verbales. Vol II. Paris: A. Colin. 2001. Les actes de langage dans le discours. Théorie et fonctionnement. Paris: Nathan.

Machado, Anna Rachel. 2003. Análise de linguagem/trabalho educacional e suas relações. Projeto de Pesquisa aprovado e subsidiado pelo Conselho de Ensino e Pesquisa da PUC/SP.

. 1998. O diário de leituras: a introdução de um novo instrumento na escola. São Paulo: Martins Fontes.

Meneghel, Stela. M. \& Lamar, Adolfo. R. 2002. Avaliação como construção social - reflexões sobre as políticas de avaliação da educação no Brasil. In: José Dias Sobrinho \& Dilvo I. Ristoff (Orgs.) Avaliação democrática - Para uma universidade cidadã. Florianópolis: Insular: 145-164.

Paveau, Marie-Anne. 1999. Le discours des instructions officielles au Lycée en 1995: jeux et enjeux énonciatifs. Pratiques, 101/102: 10-20.

Plazaola Giger, Itziar. 2004. Prescrire l'agir enseignant ? Le cas de l'allemand. In : Jean-Paul Bronckart \& Groupe LAF. (Orgs.) Agir et discours en situation de travail. Cabiers de la section des sciences de l'éducation (Genève), 103: 185-212.

Rocha, Décio; Daher, Maria del Carmen F. G. \& Sant'Anna, Vera Lúcia de Albuquerque. 2002. Produtividade das investigações sobre o trabalho. In: Maria Cecília Pérez de Souza e SiLva \& Daniel Faïta (Orgs.) Linguagem e Trabalho: construção de objetos de análise no Brasil e na França. São Paulo: Cortez : 77-92.

Saujat, Frédéric. 2002. Ergonomie de l'activité enseignante et développement de l'expérience professionnelle: une approche clinique du travail du professeur. (Tese de doutorado em Ciências da Educação. Université de Aix-Marseille I. 


\section{Anexo 1 AO PROFESSOR}

O papel fundamental da educação no desenvolvimento das pessoas e das sociedades amplia-se ainda mais no despertar do novo milênio e aponta para a necessidade de se construir uma escola voltada para a formação de cidadãos. Vivemos numa era marcada pela competição e pela excelência, em que progressos científicos e avanços tecnolo'gicos definem exigências novas para os jovens que ingressarão no mundo do trabalho. Tal demanda impõe uma revisão dos currículos, que orientam o trabalho cotidianamente realizado pelos professores e especialistas em educação no nosso país.

Assim, é com imensa satisfação que entregamos aos professores das séries finais do ensino fundamental os Parâmetros Curriculares Nacionais, com a intenção de ampliar e aprofundar um debate educacional que envolva escolas, pais, governos e sociedade e dê origem a uma transformação positiva no sistema educativo brasileiro.

Os Parâmetros Curriculares Nacionais foram elaborados procurando, de um lado, respeitar diversidades regionais, culturais, politicas existentes no país e, de outro, considerar a necessidade de construir referências comuns ao processo educativo em todas as regiões brasileiras. Com isso, pretende-se criar condições, nas escolas, que permitam aos nossos jovens ter acesso ao conjunto de conhecimentos socialmente elaborados e reconhecidos como necessa' rios ao exercício da cidadania.

Os documentos apresentados são o resultado de um longo trabalho que contou com a participação de muitos educadores brasileiros e têm a marca de suas experiências e de seus estudos, permitindo assim que fossem produzidos no contexto das discusssões pedago' gicas atuais. Inicialmente, foram elaborados documentos, em versões preliminares, para serem analisados e debatidos por professores que atuam em diferentes graus de ensino, por especialistas da educação e de outras a'reas, além de instituições governamentais e não-governamentais. As críticas e sugestões apresentadas contribui' ram para a elaboração da atual versão, que deverá ser revista periodicamente, com base no acompanhamento e na avaliação de sua implementação.

Esperamos que os Parâmetros sirvam de apoio às discussões e ao desenvolvimento do projeto educativo de sua escola, à reflexão sobre a pratica pedagógica, ao planejamento de suas aulas, à análise e seleção de materiais didáticos e de recursos tecnológicos e, em especial, que possam contribuir para sua formação e atualização profissional. 
Machado \& Bronckart: De que Modo os Textos Oficiais Prescrevem... 211

Paulo Renato Souza

Ministro da Educação e do Desporto

(BRASIL/MEC-SEF. 1998a. Parâmetros Curriculares Nacionais: terceiro e quarto ciclos do ensino fundamental: introdução aos parâmetros curriculares nacionais. Brasília: MEC/SEF. Version PDF, no site www.mec.gov.br, consultado entre 01/04/2003 a 01/07/2003.

\section{Anexo 2}

Message de Madame Brunschwig Graf

Genève, août 2000

Mesdames et Messieurs,

Chères enseignantes et chers enseignants,

L'école publique a besoin de références et de repères pour donner à l'ensemble de ses élèves la possibilité d'acquérir les connaissances et les compétences indispensables à la poursuite de leur parcours scolaire et personnel.

Ce sont les objectifs d'apprentissage et les plans d'études qui les accompagnent qui répondent à cette attente et constituent les outils indispensables sur lesquels vous devez pouvoir vous appuyer dans l'exercice de votre métier.

L'enseignement primaire est en rénovation, à Genève comme un peu partout en Suisse. L'introduction de cycles d'apprentissage de quatre ans n'a de sens que si ceux-ci cadrent avec des périodes d'apprentissage balisées, où les exigences et les attentes sont clairement posées en fonction des différentes disciplines. Il en va de même pour ce qui touche à l'évaluation, quelle que soit sa forme.

Un travail considérable s'est engagé depuis plusieurs années pour élaborer le document qui vous est remis. Il s'intègre dans un projet plus large mené au niveau de la Suisse romande où l'on s'attache maintenant à mettre au point des plans d'études cadre pour l'ensemble de l'école obligatoire.

C'est le lieu de remercier la direction générale de l'enseignement primaire et particulièrement Madame Thérèse Guerrier ainsi que les formatrices et formateurs qui ont travaillé sous sa responsabilité. Leur travail et leur engagement se sont 
vus renforcés par celles et ceux d'entre vous qui ont été appelés à examiner le projet, à faire part de leurs suggestions et de leurs critiques pour en améliorer la forme et le contenu.

Il s'agit d'un document officiel qui devient désormais la référence pour l'ensemble de nos écoles primaires. L'année scolaire 2000-2001 devrait vous permettre de vous l'approprier et vous pourrez, si vous le souhaitez, faire appel aux formations que vous estimerez nécessaires. Dès la rentrée 2001, il devra être pleinement applicable par tous. Dans le futur, il sera appelé à évoluer avec votre appui, vos expériences et selon les besoins qui ne manqueront pas de se faire sentir au cours des années à venir.

Vous êtes (sur le terrain quotidien de l'école. Vous assurez, avec vos compétences professionnelles et votre engagement, la qualité de l'école primaire genevoise. La parution des «Objectifs d'apprentissage de l'école primaire genevoise» m'offre l'occasion de souligner combien nous estimons votre apport précieux à la formation des enfants de notre canton.

Martine Brunschwig Graf

Présidente du Département de l'Instruction publique

(Direction de l'Enseignement Primaire. 2000. Les objectifs d'apprentissage de l'école primaire genevoise)

\section{Anexo 3}

\section{Planejamento: unidades e projetos}

Um planejamento anual é composto por unidades ou projetos para a abordagem de temas de trabalho escolhidos. São duas formas semelhantes de desenvolver conteúdos e objetivos para um aprendizado ativo. Uma importante diferença é que nos projetos abre-se espaço para uma participação mais ampla dos estudantes, pois várias etapas do processo são decididas em conjunto e seu produto é algo com função social real: um jornal, um livro, um mural, uma apresentação pública etc.

Na unidade de planejamento, há uma possível seqüência de etapas:

- apresentação do tema pelo professor, que pode consistir em exposição dialogada (conversa com os estudantes) ou acompanhada de algum recurso didático, 
como passar um trecho de filme, apresentar uma notícia de jornal ou outra situação concreta para iniciar a problematização. Nesta etapa, é importante a apresentação dos fatos, levantamento de interpretações, dúvidas e questões dos próprios estudantes, que o professor organiza, mas não explica completamente;

- delimitação dos problemas que serão investigados e levantamento de hipóteses para sua solução. Os conhecimentos prévios dos estudantes manifestamse em suas hipóteses ou interpretações dos problemas e devem ser registrados coletivamente, para posterior comparação com os conhecimentos sistematizados;

- investigação propriamente dita, com a utilização das fontes de informação e outros recursos didáticos, como jogos e simulação. O professor, com a participação dos estudantes, propõe as fontes mais adequadas para cada uma das questões. Durante esta etapa há confronto entre as hipóteses iniciais e as informações obtidas, e os estudantes reestruturam explicações. As diferentes atividades, como exploração bibliográfica, entrevista, experimentação, trabalho de campo ou outras, devem ser registradas, para melhor aprendizagem;

- sistematização final de conhecimentos, com a apresentação de seminário, relatório ou outras formas de conclusão, também podem compor a avaliação individual e grupal;

- realização de exercícios finais e auto-avaliação dos estudantes. Nesta etapa, como na anterior, a comparação entre os resultados e os conhecimentos prévios interessam também para o aluno reconhecer e valorizar seu processo de aprendizagem.

Brasil/MEC-SEF (1998b). Parâmetros Curriculares Nacionais: terceiro e quarto ciclos do ensino fundamental: ciências naturais: 115-131).

\section{Anexo 4}

\section{Conception de l'enseignement}

Situations d'apprentissage et activités de structuration

a) Proposer des situations d'apprentissage complexes

L'enseignant-e propose aux élèves des situations d'apprentissage complexes, dans le sens où elles obligent à mettre en réseau des savoirs et savoir-faire pour pouvoir surmonter les obstacles et résoudre les problèmes posés. 
b) Articuler les situations complexes avec des activités de structuration

Si l'on veut assurer des apprentissages solides, les situations complexes ne peuvent se concevoir sans une articulation avec des activités de structuration, d'automatisation et de consolidation de notions et savoir-faire particuliers. Il s'agit d'exercer chez les élèves le lien entre situations complexes et activités spécifiques, afin de leur permettre de donner plus de sens à ce qu'ils font et faciliter le transfert d'une situation à l'autre.

c) Reconnaître les erreurs

L'erreur fait partie du processus d'apprentissage. Les élèves expriment des opinions erronées, proposent des solutions partiellement correctes. Il convient d'identifier si les erreurs sont dues à de l'étourderie, à l'incompréhension de la tâche à accomplir ou au niveau cognitif. Cette distinction est nécessaire pour intervenir utilement. Selon le cas, il suffira d'une simple correction, d'une nouvelle explication, d'un questionnement ou encore d'une modification de l'activité proposée en tenant compte du développement cognitif.

\section{d) Différencier l'action pédagogique}

La différenciation de l'action pédagogique au sein de situations d'apprentissage doit permettre aux élèves une mise en œuvre de leur démarche et à l'enseignante des interventions ajustées. Il ne faut donc pas confondre la différenciation dans de telles situations avec l'individualisation de la tâche qui se traduit généralement par un travail différent pour chaque élève. La différenciation de l'action pédagogique peut aussi se concrétiser par le choix que fait l'enseignant-e de situations d'apprentissage, par le regroupement des élèves en fonction d'un but précis, par un plan de travail en partie différencié, des temps de travail à la maison plus personnalisés, des ateliers à choix, etc.

(Direction de l'Enseignement Primaire. 2000. Les objectifs d'apprentissage de l'école primaire genevoise.) 